\title{
Changes in Plasma Lecithin: Cholesterol Acyl Transferase Activity in Rats Fed a Cholesterol Diet
}

\author{
E. Chukwu OnyeneKe, ${ }^{*}$ E. Olisa Alumanah, and \\ Ikpendu C. ONONOGBU \\ Department of Biochemistry, University of Nigeria, Nsukka, Nigeria
}

(Received April 4, 1990)

\begin{abstract}
Summary The effect of feeding of cholesterol equivalent to 7.692 and $10.026 \mathrm{mg} / \mathrm{kg} /$ day on plasma lecithin: cholesterol acyl transferase activity in rats was examined. The enzyme activity was increased significantly in the cholesterol-fed rats $(p<0.01)$ when compared with the level in the control animals fed a normal diet and was found to be dose (amount of cholesterol incorporated) dependent. The former group also showed relative significant increases in the plasma levels of cholesteryl ester and lysolecithin $(p<0.05)$ and decreased levels of lecithin $(p<0.01)$. Changes in free cholesterol levels were, however, not statistically significant $(p>0.05)$ in the cholesterol-fed rats. The implications of these findings are discussed with respect to atherogenesis.
\end{abstract}

Key Words: cholesterol diet, LCAT

Although the rate of mortality has been reduced, cardiovascular disease still remains one of the leading causes of death in developed countries. Studies in this area are mostly preventive and have focused on ways of reducing plasma cholesterol by nutritional means. Diet plays an important role in controlling blood lipids. The effect of dietary fat on blood lipids has been studied [1-3], but the effects on lipid-metabolizing enzymes have not been studied as such, despite the fact that these enzymes are responsible for changes in plasma lipids.

Lecithin: cholesterol acyl transferase (LCAT, EC 2.3.1.43) catalyzes the transfer of fatty acids from the C-2 position of lecithin to cholesterol [4]. In humans, almost all plasma cholesteryl ester is formed by the activity of this enzyme $[5,6]$. The enzyme has been implicated in the transport of cholesterol from peripheral tissues to the liver $[6,7]$, and individuals devoid of this enzyme [8] show abnormal plasma lipoproteins [9]. In the absence of LCAT activity, both

*To whom correspondence should be addressed. 
cholesterol and triglyceride metabolisms are perturbed, and the resulting plasma lipoproteins bear little resemblance to their normal counterparts. Experiments have indicated that the modification of serum lipoproteins by LCAT [10] alters rates of cholesterol flux between cells and medium and results in a net loss of cholesterol from the cells accompanied by cellular cholesterol synthesis [11, 12]. Because most extrahepatic tissues cannot catabolize cholesterol [13], the mechanism of egress of cholesterol from cells and the involvement of LCAT in this reaction is of utmost importance since most of the cholesterol that accumulates in the aorta during atherosclerotic cardiovascular disease is in the esterified form. The hypothesis that LCAT may participate in this regulation and process of esterification of excess cholesterol in the intravascular circulation is explored in this investigation. The reported response of LCAT to nutritional factors [14] and the earlier reports of lowering of LCAT activity by a gari diet [15] prompted us to investigate the effect of cholesterol feeding on LCAT activity. Sinee cholesteryl ester is the offending lipid in atheromatous plagues, it is therefore of interest to determine the possible involvement of LCAT in atherogenesis.

\section{MATERIALS AND METHODS}

Animals and diet. Forty-five male albino rats (twelve weeks old and having an average weight of $150 \mathrm{~g}$ ) obtained from the animal house of the Faculty of Veterinary Medicine, University of Nigeria, Nsukka, were used for the study. The rats were divided into three groups (one control, A, and two experimental groups, $\mathrm{B}$ and $\mathrm{C}$ ) of fifteen rats each and housed in stainless steel cages with raised wire floors at a temperature of $30^{\circ} \mathrm{C}$ [16]. The rats were fed three different dietary regimens, A, B, and C, for a period of 4 weeks. Diet A (control) had no cholesterol, where as diets $\mathrm{B}$ and $\mathrm{C}$ (the experimental) contained 2 and $5 \%$ by weight of cholesterol, respectively, incorporated into the normal rat feed. This is equivalent to a dietary intake of $3.076,7.692$, and $10.026 \mathrm{mg} / \mathrm{kg} /$ day, respectively. Composition of each diet is presented in Table 1. Before the start of the diet, the rats were fasted overnight but allowed water ad libitum.

Enzyme assay. At weekly intervals three rats from each group were killed for analysis. Blood was collected from the animals by cardiac puncture, and plasma was separated by low-speed centrifugation at $10,000 \times g$ for $10 \mathrm{~min}$. The

Table 1. Diet composition (\% by weight).

\begin{tabular}{lccc}
\hline & \multicolumn{3}{c}{ Group } \\
\cline { 2 - 4 } Feed composition & $\mathrm{A}$ & $\mathrm{B}$ & $\mathrm{C}$ \\
& $(\mathrm{Control})$ & $(2 \%$ Cholesterol $)$ & $(5 \%$ Cholesterol) \\
\hline Maize flour & 70 & 68 & 65 \\
Fish meal & 10 & 20 & 10 \\
Groundnut cake & 20 & 2 & 20 \\
Cholesterol & - & & 5 \\
\hline
\end{tabular}


supernatant was carefully decanted and analysis was carried out immediately. Determination of total and free cholesterol in the plasma was by the method of Searcy and Bergquist [17], while lecithin and lysolecithin concentrations were determined by the method of Stewart [18] after thin-layer chromatography as suggested by Bowyer and King [19]. LCAT activity and protein content were determined by the methods of Varma and Soloff [20] and Lowry et al. [21], respectively. The enzyme activity was expressed as $\mathrm{mg}$ cholesterol ester formed per $100 \mathrm{ml}$ plasma.

Other analyses. Histological preparations of the aorta of the rats at the end of the feeding period were made as described earlier [22]. The cholesterol content of the various dietary regimens was determined by the method of Searcy and Bergquist [17]. Statistical analysis was by Student's $t$-test. All the reagents and chemicals were of analytical grade.

\section{RESULTS}

The rats consumed their daily rations satisfactorily and showed an increase in body weight. The increase in weight was in the order of group $\mathrm{A}>$ group $\mathrm{B}$ (2\% cholesterol) $>$ group C (5\% cholesterol). The dietary cholesterol intake of the various groups as determined by analysis was equivalent to $3.076 \mathrm{mg} / \mathrm{kg} / \mathrm{day}$ for group A, 7.692 for group B, and 10.026 for group C.

Changes in the mean plasma cholesterol concentration in the respective groups fed the various levels of cholesterol were as shown in Table 2. The cholesterol-fed rats, both at 2 and 5\% levels, showed progressively higher levels of cholesteryl ester when compared with the control group. These increases were statistically significant at $p<0.01$, and the increase was greater in group $\mathrm{C}$ than in group B. The total plasma cholesterol concentration in these two groups was also significantly higher $(p<0.01)$ than that of the control (group A), indicating a general increase in the lipid profile of groups B and C. Similarly, there was a corresponding increase in the free cholesterol levels in these groups, although the levels were not statistically significant $(p>0.05)$.

Table 2. Changes in mean plasma cholesterol concentration $(\mathrm{mg} / 100 \mathrm{ml}) .^{\mathrm{a}}$

\begin{tabular}{|c|c|c|c|c|c|c|c|c|c|}
\hline \multirow{3}{*}{$\begin{array}{l}\text { Time } \\
\text { on diet } \\
\text { (weeks) }\end{array}$} & \multicolumn{3}{|c|}{ Total cholesterol } & \multicolumn{3}{|c|}{ Cholesterol ester } & \multicolumn{3}{|c|}{ Free cholesterol } \\
\hline & \multicolumn{3}{|c|}{ Group } & \multicolumn{3}{|c|}{ Group } & \multicolumn{3}{|c|}{ Group } \\
\hline & $\mathrm{A}$ & B & $\mathrm{C}$ & A & B & $\mathrm{C}$ & A & $\mathrm{B}$ & $\mathrm{C}$ \\
\hline 0 & $80.4 \pm 1.2$ & $81.7 \pm 3.0$ & $76.2 \pm 0.2$ & $56.9 \pm 0.5$ & $57.2 \pm 0.8$ & $54.0 \pm 0.2$ & $23.5 \pm 0$ & \pm 1.2 & $22.2 \pm 0.4$ \\
\hline 1 & $85.7 \pm 0.7$ & $99.4 \pm 1.5$ & $126.3 \pm 1.6^{*}$ & $61.6 \pm 1.4$ & $74.5 \pm 1.4$ & $97.6 \pm 0.5^{*}$ & $24.1 \pm 0$ & \pm 0.7 & $28.7 \pm 0.8$ \\
\hline 2 & $91.3 \pm 1.6$ & $111.2 \pm 0.6^{*}$ & $151.5 \pm 1.2^{* *}$ & $60.8 \pm 1.1$ & $78.8 \pm 2.5$ & $119.6 \pm 2.0^{* *}$ & $30.5 \pm 1$ & \pm \pm 1.6 & $31.9 \pm 0.3$ \\
\hline 3 & $98.1 \pm 1.1$ & $134.6 \pm 0.4^{* * *}$ & $168.9 \pm 1.5^{* *}$ & $57.4 \pm 0.9$ & $90.8 \pm 1.3^{\text {** }}$ & " $121.6 \pm 2.8^{* * *}$ & $40.7 \pm 0$ & $3 \pm 1.5$ & $47.3 \pm 1.6$ \\
\hline $4 \quad 11$ & $10.4 \pm 0.8$ & $146.3 \pm 2.1^{* *}$ & *192.6士2.5** & $62.2 \pm 1.8$ & $93.2 \pm 4.6^{* *}$ & ${ }^{*} 136.0 \pm 3.6 * *$ & $48.2 \pm 0$ & \pm 2.0 & $56.6 \pm 1.0$ \\
\hline
\end{tabular}

$\mathrm{A}, \mathrm{B}$, and $\mathrm{C}$ represent the various diet groups as defined in Materials and Methods. ${ }^{\mathrm{a}}$ Values represent mean $\pm \mathrm{SD}$. ${ }^{*} p<0.05$ vs. corresponding group A value; ${ }^{* *} p<0.01$ vs. corresponding group A value.

Vol. 10, No. 1, 1991 
Table 3 shows the mean plasma lecithin and lysolecithin concentrations during the period of study, both of which showed an overall progressive increase for all the groups. Whereas lecithin concentrations in cholesterol-fed rats were lower than those in the controls (B: $p<0.05$; $\mathrm{C}: p<0.01$ ), these groups showed

Table 3. Changes in mean plasma lecithin and lysolecithin concentrations $(\mathrm{mg} / 100 \mathrm{ml}){ }^{\mathrm{a}}$

\begin{tabular}{|c|c|c|c|c|c|c|}
\hline \multirow{3}{*}{$\begin{array}{l}\text { Time on } \\
\text { diet } \\
\text { (weeks) }\end{array}$} & \multicolumn{3}{|c|}{ Lecithin } & \multicolumn{3}{|c|}{ Lysolecithin } \\
\hline & \multicolumn{3}{|c|}{ Group } & \multicolumn{3}{|c|}{ Group } \\
\hline & $\mathrm{A}$ & B & $\mathrm{C}$ & A & B & $\mathrm{C}$ \\
\hline 0 & $30.1 \pm 1.8$ & $27.9 \pm 0.5$ & $32.6 \pm 0.8$ & $5.0 \pm 0.9$ & $4.3 \pm 0.7$ & $5.5 \pm 1.5$ \\
\hline 1 & $37.5 \pm 1.3$ & $30.3 \pm 0.4$ & $32.8 \pm 1.1$ & $6.5 \pm 1.5$ & $7.2 \pm 0.3$ & $12.1 \pm 1.8$ \\
\hline 2 & $42.6 \pm 1.8$ & $34.7 \pm 1.2$ & $34.4 \pm 0.9^{*}$ & $9.8 \pm 0.8$ & $13.5 \pm 1.6$ & $23.9 \pm 1.0^{* *}$ \\
\hline 3 & $46.9 \pm 1.2$ & $41.8 \pm 1.5$ & $38.2 \pm 1.5^{*}$ & $14.3 \pm 1.4$ & $21.8 \pm 2.2^{* *}$ & $41.8 \pm 0.8^{* *}$ \\
\hline 4 & $58.3 \pm 2.4$ & $46.2 \pm 2.1^{*}$ & $41.5 \pm 1.7^{* *}$ & $15.6 \pm 0.6$ & $27.8 \pm 2.6^{* *}$ & $52.3 \pm 3.0^{* *}$ \\
\hline
\end{tabular}

$\mathrm{A}, \mathrm{B}$, and $\mathrm{C}$ represent the various diet groups defined in Materials and Methods. ${ }^{\mathrm{a}}$ Values represent mean $\pm \mathrm{SD} .{ }^{*} p<0.05$ vs. corresponding group A value; ${ }^{* *} p<0.01$ vs. corresponding A value.

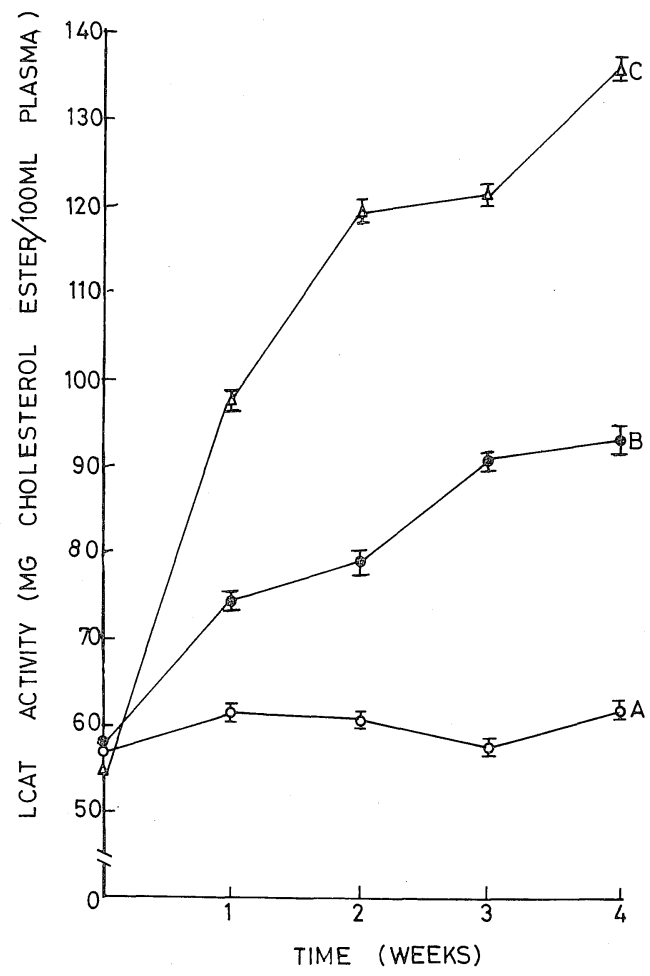

Fig. 1. Cholesterol-esterifying activity of LCAT. A, B, and C represent the various diet groups defined in Materials and Methods. 


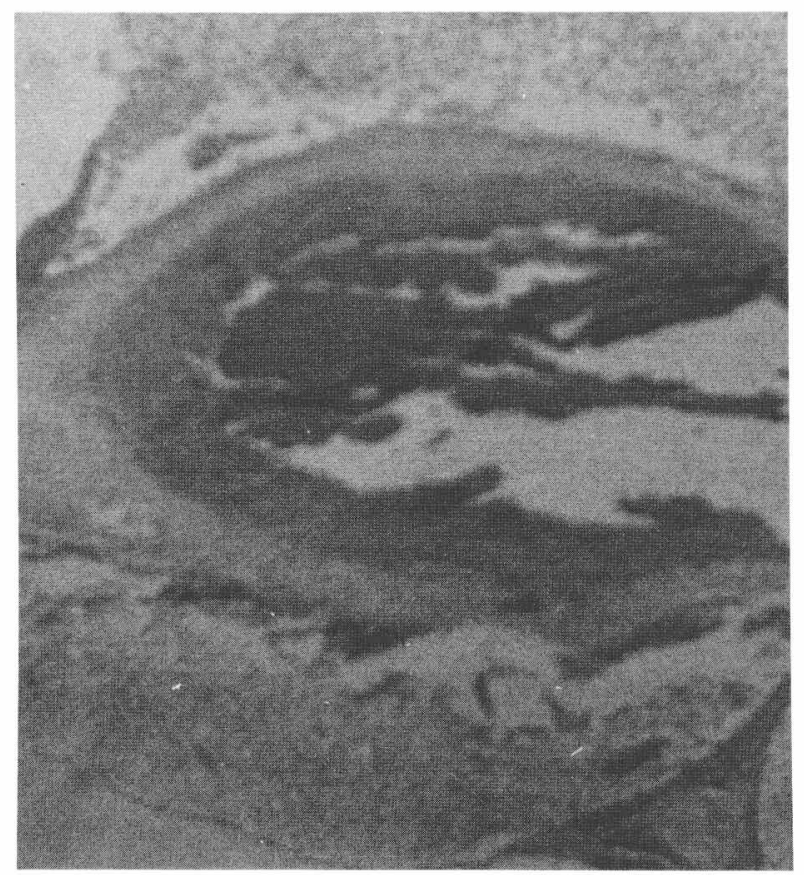

Fig. 2. Histochemical preparation of the aorta of a group $\mathrm{C}$ rat removed at the end of the diet period. Notice the massive degeneration of the arterial wall linings and evidence of movement of smooth muscle cells into the intima. Fatty streaks can be seen within the lumen of the artery.

correspondingly higher values in lysolecithin levels; and these differences were statistically significant (B: $p<0.05 ; \mathrm{C}: p<0.01$ ). However, the rise in lysolecithin levels was not proportionally reflected by a corresponding decrease in lecithin concentration.

The esterifying activity of plasma LCAT expressed as $\mathrm{mg}$ cholesterol ester formed per $100 \mathrm{ml}$ plasma is as shown in Fig. 1. The results obtained showed that exogenous cholesterol increases the esterifying activity of LCAT when compared with the control and that the increases is dose dependent. The observed differences in free cholesterol/esterified cholesterol in plasma of both groups of rats indicates that the activity of LCAT is enhanced in the presence of exogenous cholesterol.

Histochemical examination of the aorta of the rats at the end of the diet period showed massive degeneration of the arterial wall linings and movement of smooth muscle cells into the intima of the arteries in group $\mathrm{C}$ rats only. This was also followed by deposition of fatty streaks in the lumen of the arteries (Fig. 2). No such observation was made for groups A and B rats, which maintained an intact vasculature. 


\section{DISCUSSION}

The control diet represents the cholesterol dietary requirement of $200 \mathrm{mg} / \mathrm{day}$ for an average man (65 kg); group B, $500 \mathrm{mg} /$ day (the upper limit), and group C, excess dietary cholesterol intake.

The hypercholesterolemia that develops when animals are fed a high-fat diet is consistently characterized by an increase in the molecular weight of plasma low-density lipoproteins [23, 24]. Although LCAT esterifies plasma cholesterol solely at the interface of HDL and VLDL, the cholesteryl esters thus produced accumulate in all other lipoproteins [25]. Studies have indicated that there is a correlation between elevation in plasma esterified cholesterol and susceptibility to coronary heart disease [26]. Although elevation of plasma or tissue cholesterol after excessive cholesterol intake depends on the animal species, cholesterol administration has been shown to increase plasma total cholesterol in the rat [27].

The results presented here indicate clearly that cholesterol feeding increases the plasma total and esterified cholesterol concentrations and lowers the plasma lecithin level. The increase in the plasma esterified cholesterol concentration reflects an increase in the esterifying activity of LCAT, which is responsible for regulation of the plasma cholesteryl ester level $[5,6]$. Since plasma lecithin is required as the acyl donor for the transesterification reaction of LCAT, an increase in the activity level of the enzyme would result in a lowering of the plasma lecithin level, as was recorded for the cholesterol-fed rats. The increase in the lysolecithin fraction did not correspond to the decrease in the lecithin level, suggesting that the enzyme does not derive all acyl groups from lecithin. The possibility exists that LCAT could utilize other fatty acids within the lipoprotein particles for the esterification process, although this remains to be established.

Although exogenous administration of cholesterol is known to increase the plasma cholesterol concentration $[23,24]$, the results of our present study have shown that the increase is mostly in the cholesteryl ester fraction due to the increased activity of LCAT. The increase in plasma LCAT activity leading to an increase in cholesteryl ester fraction found in this work is of interest, since the offending lipid in atherogenesis is the cholesteryl ester fraction. An increase in the cholesteryl ester fraction above the plasma threshold level could possibly initiate atherogenesis. It then follows that the hypercholesterolemia that developed when the rats were fed a high-cholesterol diet is due to stimulated activity of LCAT with the result that excess cholesteryl ester is produced. If the cholesteryl ester produced cannot be effectively catabolized due to its relatively high concentration, there would be consequent deposition of the excess in the peripheral and vascular tissues resulting in atherogenesis (Fig. 2). Thus, it is evident from this study that LCAT could participate in atherogenesis since the activity level of this enzyme controls the plasma cholesteryl ester concentration. It could be argued therefore that those communities that consume a high-cholesterol diet may have elevated levels of 
LCAT activity which predisposes them to the development of atherosclerotic cardiovascular disease. This hypothesis supports the earlier finding [15] that a gari diet inhibited LCAT activity with the result that those communities that subsist on gari, like Nigeria, have a low incidence of atherosclerotic cardiovascular disease [16]. Thus, regulation of the activity level of LCAT could be beneficial for the control of atherogenesis.

\section{REFERENCES}

1. Chait, A., Onitiri, A., Nicoll, A., Rabaya, E., Davies, J., and Lewis, B. (1974): Reduction of serum triglyceride levels by poly-unsaturated fat. Atherosclerosis, 20, 347-364.

2. Ernst, N., Fisher, M., Bowen, P., Shaefer, E.J., and Levi, R.I. (1980): Changes in plasma lipids and lipoproteins after a modified fat diet, Lancet, 111-112.

3. Kritchevsky, D., Tepper, S.A., Bises, G., and Klurfeld, D.H. (1983): Influence of cocoa butter on cholesterol metabolism in rats: Comparison with corn oil, coconut oil and palm kernel oil. Nutr. Res., 3, 229-236.

4. Fielding, C.J. (1974): Phospholipid substrate specificity of purified human plasma lecithin: Cholesterol acyl transferase. Scand. J. Clin. Lab. Invest., 33, 15-20.

5. Glomset, J.A. (1962): The plasma cholesterol esterification reaction: Plasma fatty acid transferase. Biochim. Biophys. Acta, 65, 128-132.

6. Nordby, G., and Norum, K.R. (1975): Substrate specificity of lecithin: Cholesterol acyl transferase. Esterification of desmosterol, B-sitosterol, and cholecalciferol in human plasma. Scand. J. Clin. Lab. Invest., 35, 677-682.

7. Glomset, J.A. (1968): The plasma lecithin: Cholesterol, acyl transferase reaction: Review. $J$. Lipid Res., 9, 155-167.

8. Norum, K.R., and Gjone, E. (1970): Cholesterol turnover in men, in Advances in Lipid Research, ed. by Paoletti, R., and Kritehevsky, D., Academic Press, London, New York, Vol. 8, pp. 1-39.

9. Glomset, J.A., Norum, K.R., and King, W. (1970): Plasma lipoproteins in familial lecithin; cholesterol acyl transferase deficiency; lipid composition and reactivity in vitro J. Clin. Invest., 49, 1827-1937.

10. Glomset, J.A. (1976): Lecithin: cholesterol acyl transferase, in Lipoprotein Metabolism, ed. by Greten, H., Springer-Verlag, Berlin, New York, pp. 28-41.

11. Ray, E., Bellini, F., Stoudt, G., Hemperly, S., and Rothblat, G. (1980): Influence of lecithin: Cholesterol acyl transferase on cholesterol metabolism in hepatoma cells and hepatocytes. Biochim. Biophys. Acta, 617, 318-334.

12. Relimpio, A., and Iriarte, A.J. (1981): Re-evaluation of cholesterol homeostatis and atherosclerosis. J. Biol. Chem., 256, 4478-4488.

13. Pometta, D., Suenram, A., Sheybani, E., Grab, B., and James, R. (1986): HDL cholesterol levels in patients with myocardial infarction and their families. Atherosclerosis, 59, 21.

14. Fielding, C.J., and Fielding, P.E. (1980): Characteristic of triacylglycerol and partial acylglycerol hydrolysis by human plasma lipoprotein lipase. Biochim. Biophys. Acta, 620, 440-446.

15. Ononogbu, I.C., and Okpara, G.C. (1986): Effect of gari diet on lecithin: Cholesterol acyl transferase. Nutr. Rep. Int., 33, 19-87.

16. Ononogbu, I.C., and Emole, I. (1978): The effect of gari diet on rat plasma cholesterol. Atherosclerosis, 31, 101-104.

17. Searcy, R.L., and Bergquist, L.M. (1960): A new colour reaction for the quantitation of serum cholesterol. Clin. Chim. Acta, 5, 192-199.

18. Stewart, J.C.M. (1980): Colorimetric determination of phospholipids with ammonium ferrthiocyanate. Anal. Biochem., 104, 10-14.

Vol. 10, No. 1, 1991 
19. Bowyer, D.E., and King, J.P. (1977): Methods for the rapid separation and estimation of the major lipids of arteries and other tissues by thin-layer chromatography on small plates followed by microchemical assays. J. Chromatogr., 143, 473-490.

20. Varma, K.G., and Soloff, L.A. (1976): A method for the purification of milligram quantities of stable human phosphatidyl choline-cholesterol acyl transferase. Biochem. J., 155, 583599.

21. Lowry, O.H., Rosebrough, N.J., Farr, A.L., and Randall, R.J. (1951): Protein measurement with the Folin phenol reagent. J. Biol. Chem., 193, 265-275.

22. Onyeneke, E.C., and Ononogbu, I.C. (1989): Effect of gari diet on the pathological changes of the aorta, liver and the kidneys of rats. J. Clin. Biochem. Nutr., 7, 91-100.

23. Vegroesen, A.J. (1972): Dietary fat and cardiovascular disease: Possible modes of action of linoleic acid. Proc. Nutr. Soc., 31, 323-329.

24. Berg, K.A., Borrensen, H., and Dahlen, G. (1986): Serum high density lipoproteins and atherosclerotic heart diseases. Lancet, I, 499-501.

25. Zilversmith, D.B., Hughes, C.B., and Balmer, I. (1975): Stimulation of cholesterol ester exchange by lipoprotein-free rabbit plasma. Biochim. Biophys. Acta, 409, 393-398.

26. Maroko, P.R., Maclean, D., Ribeiro, L.G.T., and Braunwald, E. (1979): Pharmacological limitations of infarct size: Enzymatic, electrocardiographic, and morphological studies in the experimental animal and man, in Enzymes in Cardiology, ed. by Hearse, J., and de Leiris, J., John Wiley and Sons, New York, pp. 529-555.

27. Kummerow, F.A. (1982): The possible involvement of dietary fats in atherosclerosis. Prog. Lipid Res., 21, 743-746. 